\title{
Solubility of Anthracene in Binary Alkane + 2-Methyl-1-propanol Solvent Mixtures
}

\author{
Anita I. Zvaigzne, Joshua Wolfe, and William E. Acree, Jr." \\ Department of Chemistry, University of North Texas, Denton, Texas 76203-5068
}

\begin{abstract}
Experimental solubilities are reported for anthracene dissolved in seven binary mixtures containing 2-methyl1-propanol with hexane, heptane, octane, cyclohexane, methylcyclohexane, 2,2,4-trimethylpentane, and tertbutylcyclohexane at $25^{\circ} \mathrm{C}$. Results of these measurements are used to test two mathematical representations based upon the combined nearly ideal binary solvent (NIBS)/Redlich-Kister equation and modified Wilson model. For the systems studied, the combined NIBS/Redlich-Kister and modified Wilson equations were found to provide very reasonable mathematical representations with deviations between experimental and back-calculated values being on the order of $\pm 1.5 \%$ or less.
\end{abstract}

\section{Introduction}

Solid-liquid equilibrium data of organic nonelectrolyte systems are becoming increasingly important in the petroleum industry, particularly in light of present trends toward heavier feedstocks and known carcinogenicity/mutagenicity of many of the larger polycyclic aromatic compounds. Solubility data for a number of polycyclic aromatic hydrocarbons (i.e., anthracene and pyrene) and heteroatom polynuclear aromatics (i.e., carbazole, dibenzothiophene, and xanthene) have been published in the recent chemical literature $(1-6)$. Despite efforts by experimentalists and scientific organizations, in terms of both new experimental measurements and critically-evaluated data compilations, there still exist numerous systems for which solubility data are not readily available.

To address this problem, researchers have turned to group contribution methods and semiempirical expressions to predict desired quantities. Group contribution methods have proved fairly successful in estimating solid solubility in pure and binary solvent mixtures from structural information. Practical application though is limited to systems for which all group interaction parameters are known. Generally, interaction parameters are evaluated from solid-liquid and liquid-vapor equilibrium data. It is important that the data base contain as many different functional groups as possible, preferably with adequate representation from both monoand multifunctional solute/solvent molecules to permit evaluation of potential synergistic effects. The data base should contain sufficient experimental values near infinite dilution in the event that one wishes to determine separate interaction parameters for finite concentration and infinite dilution activity coefficient predictions. The UNIFAC model (7) now has two sets of group interaction parameters, with the publication of the infinite dilution values by Bastos et al. (8).

Continued development of solution models for describing the thermodynamic properties of a solute in binary solvent systems requires that a large data base be available for assessing the applications and limitations of derived expressions. Currently, only a limited data base exists for crystalline nonelectrolyte solubility in binary solvent mixtures. For this reason, anthracene solubilities were determined in seven binary alkane + 2-methyl-1-propanol solvent mixtures.

* To whom correspondence should be addressed.
Table 1. Experimental Mole Fraction Solubilities of Anthracene (A) in Binary Alkane (B) + 2-Methyl-1-propanol (C) Solvent Mixtures at $25.0^{\circ} \mathrm{C}$

\begin{tabular}{|c|c|c|c|c|c|}
\hline$x_{\mathrm{c}}{ }^{\circ}$ & $x_{\mathrm{A}}^{\text {sat }}$ & $x_{c}{ }^{0}$ & $x_{A^{\text {tat }}}$ & $x_{C^{\circ}}$ & $x_{\mathrm{A}}^{\text {eat }}$ \\
\hline \multicolumn{6}{|c|}{ Hexane (B) + 2-Methyl-2-propanol (C) } \\
\hline 0.0000 & 0.001274 & 04807 & 0.001063 & 0.8524 & \\
\hline & & & & & \\
\hline & & & & & \\
\hline \multicolumn{6}{|c|}{ Heptane (B) + 2-Methyl-1-propanol (C) } \\
\hline & 0.001 & & & & \\
\hline & & & & & \\
\hline & & & & & \\
\hline \multicolumn{6}{|c|}{ Octane (B) + 2-Methyl-1-propanol (C) } \\
\hline & 0001 & & & & \\
\hline & & & & & \\
\hline & & & & & \\
\hline \multicolumn{6}{|c|}{ Cyclohexane (B) + 2-Methyl-1-propanol (C) } \\
\hline & 0.001553 & & & & \\
\hline & & & & & \\
\hline & & & & & \\
\hline \multicolumn{6}{|c|}{ Methylcyclohexane (B) + 2-Methyl-1-propanol (C) } \\
\hline & & & & & \\
\hline & & & & & \\
\hline & & & & & 0 \\
\hline \multicolumn{6}{|c|}{ 2,2,4-Trimethylpentane (B) + 2-Methyl-1-propanol (C) } \\
\hline & 0.001074 & 0.5402 & 0.000 & & 0.0005 \\
\hline & & & & & \\
\hline & & & & & 0.000470 \\
\hline \multicolumn{6}{|c|}{ tert-Butylcyclohexane (B) + 2-Methyl-1-propanol ( } \\
\hline & & & & & \\
\hline & & & & & 574 \\
\hline 3238 & 16 & & 0.000990 & 1.000 & 0.000470 \\
\hline
\end{tabular}

Results of these measurements are used to further test the descriptive abilities of several previously derived expressions.

\section{Experimental Methods}

Anthracene (Aldrich, 99.9+\%) was used as received. Cyclohexane (Aldrich, HPLC), hexane (Aldrich, 99\%), heptane (Aldrich, HPLC), octane (Aldrich, 99+\%, anhydrous), methylcyclohexane (Aldrich, 99+\%, anhydrous), 2,2,4-trimethylpentane (Aldrich, HPLC), and tert-butylcyclohexane (Aldrich, 99\%) were stored over molecular sieves to reduce trace amouts of water shortly before use. 2-Methyl-1-propanol (Aldrich, 99+\%, anhydrous) was stored over both anhydrous sodium sulfate and molecular sieves before being fractionally distilled. Gas chromatographic analysis showed solvent purities to be $99.7 \mathrm{~mol} \%$ or better. Karl-Fisher titration gave 
Table 2. Mathematical Representation of Anthracene Solubilities in Several Alkane (B) + 2-Methyl-1-propanol (C) Solvent Mixtures

\begin{tabular}{|c|c|c|c|c|c|c|}
\hline & \multicolumn{2}{|c|}{ two-param eq 1} & \multicolumn{2}{|c|}{ three-param eq 1} & \multicolumn{2}{|c|}{ eq 2} \\
\hline & $S_{i}^{a}$ & $\% \operatorname{dev}^{b}$ & $S_{i}^{a}$ & $\% \operatorname{dev}^{b}$ & $\overline{\Lambda_{i j}}$ adj c & $\% \operatorname{dev}^{b}$ \\
\hline hexane + 2-methyl-1-propanol & $\begin{array}{r}1.267 \\
-0.080\end{array}$ & 1.2 & $\begin{array}{r}1.177 \\
-0.032 \\
0.322\end{array}$ & 0.5 & $\begin{array}{l}1.557 \\
1.417\end{array}$ & 0.6 \\
\hline heptane +2 -methyl-1-propanol & $\begin{array}{r}1.356 \\
-0.350\end{array}$ & 1.1 & $\begin{array}{r}1.284 \\
-0.301 \\
0.266\end{array}$ & 0.7 & $\begin{array}{l}1.265 \\
1.721\end{array}$ & 0.5 \\
\hline octane + 2-methyl-1-propanol & $\begin{array}{r}1.540 \\
-0.570\end{array}$ & 1.4 & $\begin{array}{r}1.422 \\
-0.464 \\
0.447\end{array}$ & 0.4 & $\begin{array}{l}1.141 \\
1.969\end{array}$ & 0.5 \\
\hline cyclohexane + 2-methyl-1-propanol & $\begin{array}{l}1.214 \\
0.148\end{array}$ & 1.3 & $\begin{array}{l}1.116 \\
0.172 \\
0.341\end{array}$ & 0.3 & $\begin{array}{l}2.197 \\
1.249\end{array}$ & 0.6 \\
\hline methylcyclohexane + 2-methyl-1-propanol & $\begin{array}{r}1.462 \\
-0.070\end{array}$ & 1.8 & $\begin{array}{l}1.342 \\
0.121 \\
0.430\end{array}$ & 0.6 & $\begin{array}{l}1.961 \\
1.501\end{array}$ & 0.9 \\
\hline 2,2,4-trimethylpentane + 2-methyl-1-propanol & $\begin{array}{r}1.090 \\
-0.221\end{array}$ & 1.5 & $\begin{array}{r}0.972 \\
-0.100 \\
0.462\end{array}$ & 0.4 & $\begin{array}{l}1.133 \\
1.525\end{array}$ & 0.9 \\
\hline tert-butylcyclohexane + 2-methyl-1-propanol & $\begin{array}{r}1.688 \\
-0.549\end{array}$ & 1.4 & $\begin{array}{r}1.576 \\
-0.435 \\
0.432\end{array}$ & 0.1 & $\begin{array}{l}1.345 \\
2.017\end{array}$ & 0.5 \\
\hline
\end{tabular}

${ }^{a}$ Combined NIBS/Redlich-Kister curve-fit parameters are ordered as $S_{0}, S_{1}$, and $S_{2} \cdot{ }^{b}$ Deviation $\left.(\%)=(100 / N) \Sigma \mid \ln \left[\left(x_{\mathrm{A}}^{\text {sat }}\right)^{\text {calc }} /\left(x_{\mathrm{A}}^{\text {aat }}\right)^{\text {exp }}\right)\right] \mid$. ${ }^{c}$ Adjustable parameters for the modified Wilson equation are ordered as $\Lambda_{\mathrm{BC}}{ }^{\mathrm{adj}}$ and $\Lambda_{\mathrm{CB}}{ }^{\text {adj. }}$.

a water content (mass/mass $\%$ ) of $<0.01 \%$ for 2 -methyl-1propanol. Binary solvent mixtures were prepared by mass so that compositions could be calculated to 0.0001 mole fraction.

Excess solute and solvent were placed in amber glass bottles and allowed to equilibrate in a constant-temperature water bath at $25.0 \pm 0.1{ }^{\circ} \mathrm{C}$ for several days. Attainment of equilibrium was verified by repetitive measurements after several additional days and by approaching equilibrium from supersaturation by preequilibrating the solutions at a higher temperature. Aliquots of saturated anthracene solutions were transferred through a coarse filter into a tared volumetric flask to determine the amount of sample and diluted quantitatively with methanol. Concentrations were determined spectrophotometrically at $356 \mathrm{~nm}$ on a Bausch and Lomb Spectronic 2000. Experimental anthracene solubilities in seven binary alkane + 2-methyl-1-propanol mixtures studied are listed in Table 1. Numerical values represent the average of between four and eight independent determinations, with the measured values being reproducible to within $\pm 1.3 \%$.

\section{Results and Discussion}

Acree and co-workers $(9,10)$ suggested possible mathematical representations for isothermal solubility data based upon either a combined NIBS/Redlich-Kister model

$$
\begin{array}{r}
\ln x_{\mathrm{A}}^{\mathrm{sat}}=x_{\mathrm{B}}{ }^{\circ} \ln \left(x_{\mathrm{A}}{ }^{\mathrm{sat}}\right)_{\mathrm{B}}+x_{\mathrm{C}}{ }^{\circ} \ln \left(x_{\mathrm{A}}{ }^{\mathrm{sat}}\right)_{\mathrm{C}}+ \\
x_{\mathrm{B}}{ }^{\circ} x_{\mathrm{C}}{ }^{\circ} \sum_{i=0}^{n} S_{i}\left(x_{\mathrm{B}}{ }^{\circ}-x_{\mathrm{C}}{ }^{\circ}\right)^{i}
\end{array}
$$

or modified Wilson equation (11)

$$
\begin{array}{r}
\ln \left[a_{\mathrm{A}}(s) / x_{\mathrm{A}}{ }^{\mathrm{Bat}}\right]=1-x_{\mathrm{B}}{ }^{\circ}\left\{1-\ln \left[a_{\mathrm{A}}(s) /\left(x_{\mathrm{A}}{ }^{\mathrm{sat}}\right)_{\mathrm{B}}\right]\right\} / \\
\left(x_{\mathrm{B}}{ }^{\circ}+x_{\mathrm{C}}{ }^{\circ} \Lambda_{\mathrm{BC}}{ }^{\mathrm{adj}}\right)-x_{\mathrm{C}}{ }^{\circ}\left\{1-\ln \left[a_{\mathrm{A}}{ }^{\left.\left.(s) /\left(x_{\mathrm{A}}{ }^{\mathrm{sat}}\right)_{\mathrm{C}}\right]\right\} /}\right.\right. \\
\left(x_{\mathrm{B}}{ }^{\circ} \Lambda_{\mathrm{CB}}{ }^{\mathrm{adj}}+x_{\mathrm{C}}{ }^{\circ}\right)
\end{array}
$$

where the various $S_{i}$ and $\Lambda_{i j}{ }^{\text {adj }}$ "curve-fit" parameters can be evaluated via least-squares analysis. In eqs 1 and $2 x_{B}^{\circ}$ and $x_{\mathrm{C}}{ }^{\circ}$ refer to the initial mole fraction composition of the binary solvent calculated as if the solute were not present, $a_{\mathrm{A}}(s)$ is the activity of the solid solute, and $\left(x_{\mathrm{A}}^{\mathrm{sat}}\right)_{i}$ is the saturated mole fraction solubility of the solute in pure solvent $i$. The numerical value of $a_{\mathrm{A}}(s)=0.01049$ (12) used in the modified Wilson computations was calculated from

$$
\ln a_{\mathrm{A}}(s)=-\Delta_{\text {fus }} H_{\mathrm{A}}\left(T_{\mathrm{mp}}-T\right) /\left(R T T_{\mathrm{mp}}\right)
$$

where $\Delta_{\text {fus }} H_{\mathrm{A}}$ is the molar enthalpy of fusion at the normal melting point temperature of the solute, $T_{\mathrm{mp}}$.

The ability of eqs 1 and 2 to mathematically represent the experimental solubility of anthracene in the seven binary alkane + 2-methyl-1-propanol solvent systems is summarized in Table 2 in the form of curve-fit parameters and percent deviations in back-calculated solubilities for the twoparameter and three-parameter expressions. Careful examination of Table 2 reveals that both representations provide very reasonable mathematical descriptions for how the solubility of anthracene varies with solvent composition. For the most part, back-calculated and experimental values differ by less than $\pm 1.5 \%$, which is comparable to the experimental uncertainty. From a computational standpoint, eq 1 will likely be preferred because most research groups involved in reporting thermodynamic properties have computer programs for evaluating the Redlich-Kister coefficients. With this idea in mind, we recommend not only that the future presentation of experimental isothermal solubility data for slightly soluble solid solutes dissolved in binary solvent mixtures include a tabulation of the actual observed values but, if possible, that the solubility data be mathematically represented by eq 1 . Realizing that a single equation will not be applicable to all systems encountered, we further suggest eq 2 as an alternative mathematical representation for systems having extremely large solubility ranges and/or highly asymmetrical $\ln x_{\mathrm{A}}^{\text {sat }}$ versus $x_{B}{ }^{\circ}$ curves, such as the carbazole + alkane + tetrahydropyran systems reported previously (10).

\section{Literature Cited}

(1) Zvaigzne, A. I.; Acree, W. E. Jr. J Chem. Eng Data 1994, 39, 114

(2) Zvaigzne, A. I.; Acree, W. E., Jr. J. Chem. Eng. Data 1994, 39, 117.

(3) McCargar, J. W.; Acree, W. E., Jr. Phys. Chem. Liq. 1987, 17, 123. 
Journal of Chemical and Engineering Data, Vol. 39, No. 3, 1994543

(4) McCargar, J. W.; Acree, W. E., Jr. J. Pharm. Sci. 1987, 76, 572.

(5) Acree, W. E., Jr. Phys. Chem. Liq. 1990, 22, 157.

(6) Coon, J. E.; Sediawan, W. B.; Auwaerter, J. E.; McLaughlin, E. J. Solution Chem. 1988, 17, 519 .

(7) Fredenslund, A.; Jones, R. L.; Prausnitz, J. M. AIChE J. 1975, 21, 1086.

(8) Bastos, J. C.; Soares, M. E.; Medina, A. G. Ind. Eng. Chem. Res. $1988,27,1269$.

(9) Acree, W. E., Jr.; Zvaigzne, A. I. Thermochim. Acta 1991, 178, 151.

(10) Acree, W. E. Jr.; McCargar, J. W.; Zvaigzne, A. I.; Teng, I.-L. Phys. Chem. Liq. 1991, 23, 27

(11) Comer, J. F.; Kopecni, M. M. Anal. Chem. 1990, 62, 991.
(12) Acree, W. E., Jr.; Rytting, J. H. J. Pharm. Sci. 1983, 72, 292.

Received for review October 22, 1993. Accepted March 8, 1994.๑ This research was supported in part by a grant from the National Science Foundation (Grant No. CTS-8922485). J.W. also thanks the U.S. Department of Education for support provided to him under the Upward Bound Math and Science Program.

- Abstract published in Advance ACS Abstracts, April 15, 1994. 